\title{
Experimental study on dynamic characteristics of foundation for large turbine-generator set \\ Lu Bing ${ }^{1, a}$ and Qu Tiejun ${ }^{1, b}$
}

${ }^{1}$ School of Civil Engineering,North China University of Technology,Beijing100144,China

alubingbj@163.com, batj@ncut.edu.cn

Keywords: turbine-generator; model test; modal analysis; response prediction

Abstract. Based on a large turbine-generator foundation in the actual project, dynamic characteristics of 1:10 model of this foundation are obtained from modal analysis of the random excitation method. Natural frequency,mode shapes and damping ratio of the structure are acquired. The results of basic vibrating displacement under operation condition are obtained according to the the vibration analysis of response prediction. Besides, using hammer pulse method to actually measure the support dynamic stiffness of bearing pedestal of this turbine-generator, to examine whether the support dynamic stiffness of this foundation meet the requirements of the current specifications. Finally, the results shows that dynamic characteristics of the foundation perform well and the structural design is safe and reasonable.

\section{Introduction}

As the core equipment of power plants, it is of great significance for the stable operation of the turbine unit to carry out studies about the dynamic characteristics and seismic safety of turbine-generator foundation. In this paper, the analysis results of vibration characteristic test do the spade work for further predicting the structure response of the forced vibration which is under the action of equipment disturbances and the structure seismic response which is under the action of earthquake.

\section{Description of model test}

\section{Model design and construction}

Based on the similarity theory, the similarity relation between prototype and model are shown in table 1. Model material is the same as prototype, which uses bar and concrete. Reinforcement ratio is determined by prototype foundation's. Concrete grade is C40. Longitudinal reinforcement of beam and column choose HRB400 steel bar with $12 \mathrm{~mm}$ in diameter, while stirrup use HPB300 with 6mm in diameter. Test model is shown in figure 1.

Table 1 Similarity relation

\begin{tabular}{cccc}
\hline Physical quantity & Model / prototype & Physical quantity & Model / prototype \\
\hline length & $1: 10$ & force & $1: 100$ \\
time & $1: 10$ & acceleration & $10: 1$ \\
strain & $1: 1$ & natural frequency & $10: 1$ \\
volume & $1: 1000$ & period & $1: 10$ \\
density & $1: 1$ & damp & $1: 100$ \\
elastic ratio & $1: 1$ & displacement & $1: 10$ \\
mass & $1: 1000$ & dynamic amplification factor & $1: 1$ \\
stiffness & $1: 10$ & & \\
\hline
\end{tabular}

\section{Excitation method}

This model test adopts a method of three-point space excitation and multi-point space measurement, which refers to choose three points as the excitation point and then excite respectively from direction of $\mathrm{X}, \mathrm{Y}$ and $\mathrm{Z}$ axis. 


\section{Measurement points arrangement and excitation points selection}

According to the characteristics of the model structure,the arrangement position of measuring points includes: 1) points of vibration forcing; 2) intersection points of vertical and horizontal beam; 3) crucial points of column. There were 137 points in all. Arrangement of measuring points is shown in figure 2.

Excitation points can't choose from vibrational nodes, and ensure that the excitation energy are uniformly distributed throughout the base. In the end,the point 90 is selected as Y excitation point, the point 146 is selected as $\mathrm{X}$ and the point 147 is $\mathrm{Z}$.

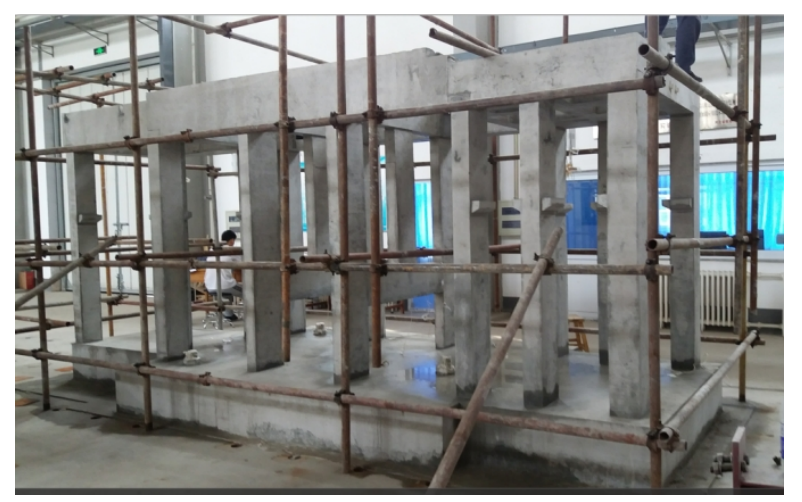

Figure 1 Test model

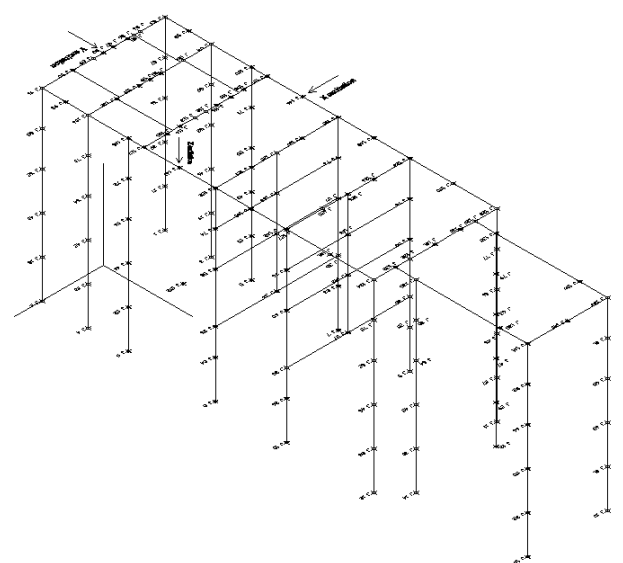

Figure 2 Arrangement of measuring points

\section{The test results}

\section{Vibration characteristics of the foundation}

Natural frequencies and vibration mode of the foundation structure can be obtained by advanced LMS modal analysis software. Figure 3 are some typical vibration types.

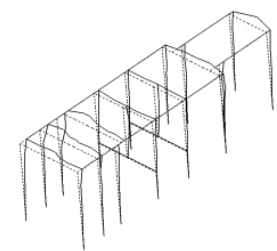

1st order $1.093 \mathrm{~Hz}$

Longitudinal horizontal translation

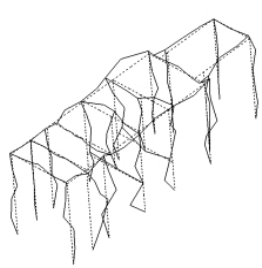

Seventh order $4.780 \mathrm{~Hz}$ Longitudinal and transversal coupling translation low-pressure cylinder

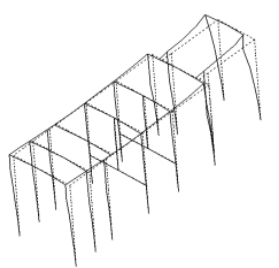

2nd order $1.791 \mathrm{~Hz}$

Horizontal transverse twist

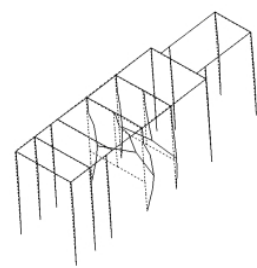

Twelfth order $7.241 \mathrm{~Hz}$ between frameworks of

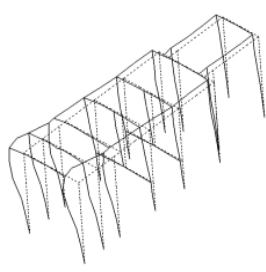

3rd order $2.261 \mathrm{~Hz}$

Horizontal lateral translation

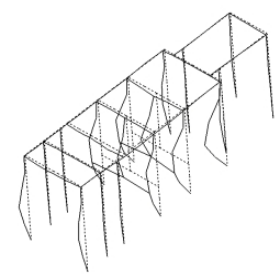

Twenty-sixth order $13.380 \mathrm{~Hz}$ of column

Figure 3 Typical vibration types

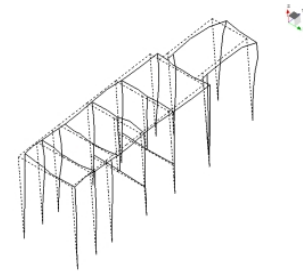

Fifth order $4.374 \mathrm{~Hz}$ Horizontal transverse bending

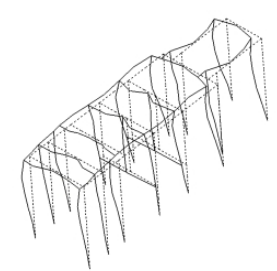

$101 \mathrm{st}$ order $51.545 \mathrm{~Hz}$ Platen's vertical bending vibration (Close vibration mode of HP'rotor in first critical speed )

The frequency distribution table shows that lowand closely spaced natural frequencies plays important roles in the operation stability of thermal power generating units. To be specific, natural frequency of vibration within $60 \mathrm{~Hz}$ exists 113 orders. Among them, the natural frequencies within 20 $\mathrm{Hz}$ account for nearly $40 \%$, which shows low frequencies hold the great proportion. 
From vibration types, the main vibration modes can be judged spatial modes. Besides, the previous vibration mode shapes of this foundation mainly covers the whole vibration mode shapes of the platen, while the vibration of the pillars show up in 20 order later.

To watch frequency distribution between $45 \mathrm{~Hz}$ to $55 \mathrm{~Hz}$, there are still some natural frequenencies of vibration for the range of the unit operating frequency.Vibrational modes mostly show vertical vibration and swing of the platen, which approach the rotor critical speeds of high-pressure cylinder. Therefore, generator units should pass this critical speeds quickly in the process of running and aviod to use electric heater in case of resonance between pedestal and the thermal power generating units.

\section{Response prediction}

When the power equipment does rotary motion, it will generate the centrifugal force, which can be transferred to the turbine foundation through the bearing components. It's consequently known as disturbances that can result in forced vibration of foundation. The dynamic machine foundation design codes have specifically requirements at the disturbances: For the working speed of $3000 \mathrm{r} / \mathrm{min}$ of turbo-generator set, vertical disturbances are determined by $20 \%$ weight of the rotor. The rotor quality is provided by manufacturers of the steam turbine generator set. Taking disturbance spectrum as input, the forced vibration response of this base can be obtained as output based on mode analysis.

The response prediction can output three kinds of dynamic response, which includes displacement, velocity and acceleration. The specification give a definite require on displacement response: In the working speed range, the allowable amplitude of vibration displacement should be less than $20 \mu \mathrm{m}$; During the initiation process, the vibration linear displacement should be less than $30 \mu \mathrm{m}$. Figure 4 are forced vibration response curves (amplitude- frequency curves) in the direction of X, Y, Z.

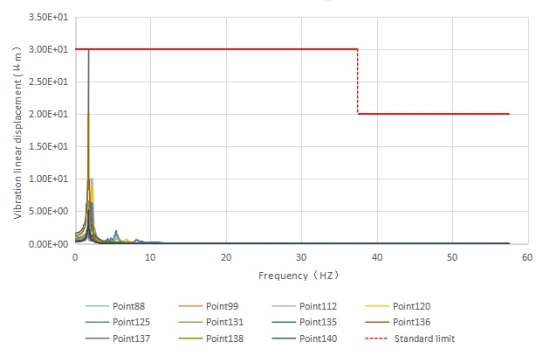

$\mathrm{X}$-axis amplitude- frequency curve

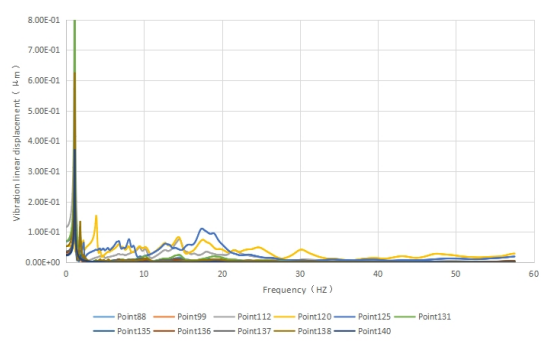

Y-axis amplitude- frequency curve

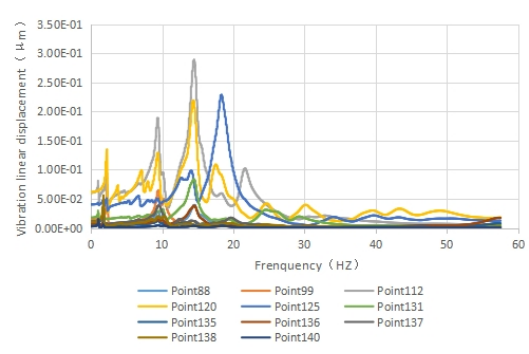

Z-axis amplitude- frequency curve Figure 4 Forced vibration response curves

\section{Dynamic stiffness}

Dynamic stiffness plays crucial role on measuring structure dynamic characteristics, it not only directly affects the safe operation of large turbine unit, but also influences its life. In this experiment, hammering method is used to measure dynamic stiffness of the bearing pedestal. Therefore, when the disturbances on each bearing seat are in a state of working frequency $(50 \mathrm{~Hz})$, the dynamic stiffness can be measured as shown in table 2.

Table 2 Dynamic stiffness of bearing pedestal under disturbances in frequency of $50 \mathrm{~Hz}\left(\times 10^{6} \mathrm{kN} / \mathrm{m}\right)$

\begin{tabular}{clllllllll}
\hline Direction & $1 \#$ & $2 \#$ & $3 \#$ & $4 \#$ & $5 \#$ & $6 \#$ & $7 \#$ & $8 \#$ & $9 \#$ \\
\hline $\mathrm{X}$ & 47.5 & 26.2 & 42.2 & 34.3 & 38.1 & 65.7 & 20.0 & 37.2 & 30.4 \\
$\mathrm{Y}$ & 7.45 & 12.2 & 11.9 & 14.8 & 11.5 & 10.5 & 13.1 & 69.6 & 23.3 \\
\hline
\end{tabular}

This test selects the Dongfang turbine Co. LTD standard (DTC for short), which is relatively strict: 
when the unit are operating in the rated speed range of frequency $(40 \sim 60 \mathrm{~Hz})$, dynamic stiffness of bearing seat should be greater than $4 \times 10^{6} \mathrm{kN} / \mathrm{m}$.Dynamic stiffness curves of each bearing pedestal are shown in figure 5 and the black dotted line is DTC standard.

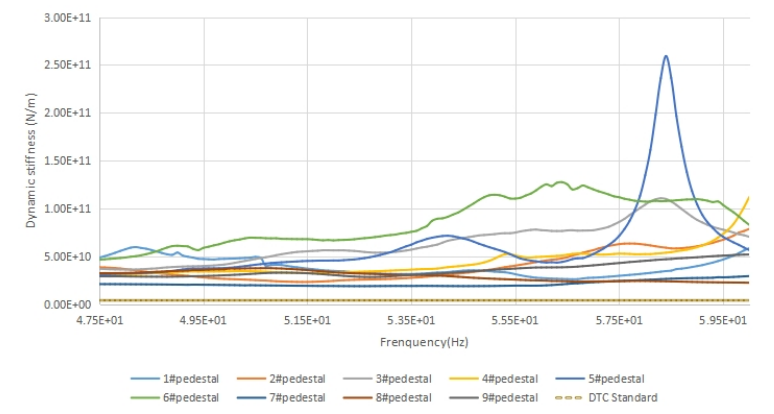

$\mathrm{X}$-axis dynamic stiffness

Figure 5 Dynamic stiffness curves

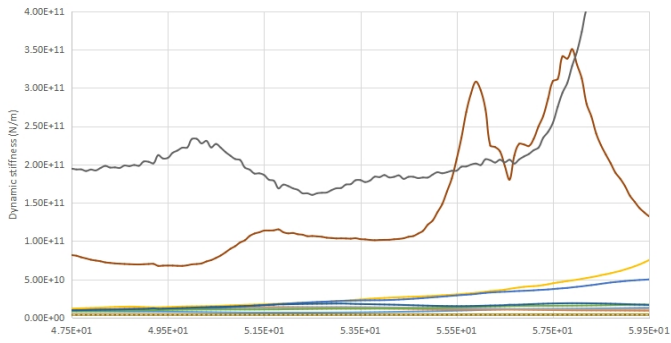

Z-axis dynamic stiffness

From the graph, the dynamic stiffness of each bearing seat can satisfy the standard requirements even by strict DTC standards.

\section{Conclusion}

Based on dynamic characteristics of the testing results, it can be concluded from the following several aspects:

(1) The natural frequencies of the infrastructure concentrates on the low frequency band, and the density distribution in operating frequency range is relatively lower, which contribute to the stable operation of this generating unit.

(2) Basic mode mainly manifests as spatial modes and fore some order shapes of vibration take the form of platen's global vibration. These vibrational modes that are dominated by whole translation and swing do relatively less harm to unit shafting.

(3)Dynamic stiffness testing results show that deformation performances of bearing blocks during resisting dynamic loads could meet the requirements.

(4)Response prediction results show that the maximal linear displacement of each disturbances point are much less than that of the allowable amplitude. There has not appeared much bigger vibration displacement near the critical rotate speed of rotor system and around operating frequency.

The large turbine-generator base is designed reasonably and safely. Meanwhile,the dynamic characteristics is relatively good and enough to satisfy actual requirements of the project application .

\section{References}

[1] Industry standard of the People's Republic of China,JGJ/T 101-2015 Test procedures of building aseismicity[S]. Beijing: China Construction Industry Press, 2015.

[2] The national standard of the People's Republic of China,GB50040-1996 Dynamic machine foundation design code[S]. Beijing: AQSIQ (CN-GB) , 1996.

[3] The national standard of the People's Republic of China,GB50011-2010 Code of seismic design 
of building[S].Beijing: China Construction Industry Press, 2010.

[4] ZhangLi.The modal analysis and experiment[M].Beijing: Tsinghua university press,2011. 